\title{
Knowledge, awareness and attitude about Breast lump among females An observational study
}

\author{
Research Article
}

\section{Ishwari Gaikwad', Pradnya Deepak Dandekar²*}

\author{
1. Scholar, 2. Professor \& Head, Department of Kriyasharir, \\ Mahatma Gandhi Ayurved College, Hospital \& Research Centre, Salod (H), Wardha.
}

\begin{abstract}
Background: Breast lump is considered as carcinogenic unless it is tested and diagnosed other than this. Today in India, it is one of the leading causes of cancer deaths among women. Only early detection and early medical intervention could decrease its mortality rate. Knowledge and awareness of palpation of breast lumps and attitude to get diagnosed at earliest is very important. Aim and Objectives: The study is designed to assess knowledge, awareness and attitude towards screening of Breast lumps among females. Materials and Methods: It is a questionnaire based an observational study. Those females above age of 14 years; attending Hospital were selected for the study with their consent. Data was collected by using self-structured and validated questionnaire. Total 100 females' data was collected and analysed. Observation and Result: Of the total sample, approximately $89 \%$ of subjects were found to have heard of Breast Cancer and $41 \%$ had knowledge that Breast lump may be a sign of Breast Cancer. 22\% females have heard about Breast self-examination (BSE) as an early diagnostic tool. Only $8 \% \&$ $14 \%$ knew about importance of Clinical Breast examination (CBE)\& mammography respectively. Awareness towards screening was found to be very low. Conclusion: The results revealed that, although knowledge about Breast lump is adequate up to certain limit but they do not have a comprehensive understanding of the condition. Thus, there is an urgent need to promote knowledge, awareness and health literacy among the society.
\end{abstract}

Key Words: Breast lump, Breast Cancer, Breast self-examination, Clinical Breast examination.

\section{Introduction}

Breast lump diseases are one of the most common diseases in India which include inflammatory, congenital, hormonal mastopathy, traumatic, benign and malignant neoplastic conditions. Breast lump is the most common reason for presenting to surgery department. It is a source of anxiety to a female when it is discovered. Annually, around 200,000 cases of breast diseases are diagnosed (1). The usual management of a breast mass is based on the assumption that the mass is cancerous until proven otherwise.

There has been a significant increase in the incidence of breast cancer over the years and it continues to raise steadily (2). Breast cancer related mortality is eminent. It is the fifth highest due to cancer and the most common cause of death among women (3). In India, interventions need to be done to guide and educate people about the risk factors, importance of screening and management of Breast lumps.

Benign diseases can be classified as epithelial and stroma proliferations, inflammatory, neoplasm and

\section{* Corresponding Author:}

\section{Pradnya Deepak Dandekar}

Professor \& Head, Department of Kriyasharir

Mahatma Gandhi. Ayurved College, Hospital \& Research Centre, Salod (H),

Wardha, India

Email Id: pradnya.dandekar@,dmimsu.edu.in developmental anomalies. Benign breast diseases are more prevalent as compared to malignant and inflammatory (4). Fibro adenomas are in greater frequency among the population, constituting half of all cases of benign diseases (5). While most reports indicate that breast lumps are predominantly benign and mostly non proliferative epithelial lesions, there has, however, been an increasing recognition of the risk of developing cancer from the various forms of premalignant lesions (6).

Breast cancer accounts for $45 \%$ of all cancer in females aged $25-49$ years and $34 \%$ of all cancer in the 50-74 year age group in the United Kingdom (7). Though breast cancer is rare in younger age groups, it is generally more aggressive in this category, with lower survival rates (8). An international survey showed poor awareness of risk factors for breast cancer among university students from 23 countries, compared to older women (9). This emphasizes the importance of promoting awareness among young women about not only breast cancer but any palpable mass in breast and strategies available for its screening are very much essential. Knowledge about this and attitude about breast lumps early detection by using different methods plays a pivotal role in prevention of breast cancer. We conducted this study to evaluate awareness of the female about the breast lumps early detection, strategies available, self-doing technique, sources of information available and attitude of the females towards its screening among females visiting Mahatma Gandhi Ayurved Hospital, Wardha. 
Aim

The study was designed to assess knowledge, awareness and attitude towards screening of Breast lumps among females.

\section{Objectives}

- To assess the level of knowledge and awareness of breast lumps and its early detection strategies in females.

- To determine the attitude of females towards screening.

\section{Material and Methods}

- Study design - This was an observational study based on questionnaire.

- Study place: Study conducted in Mahatma Gandhi Ayurved Hospital, Salod(H),Wardha, which is NABH accredited learning Institute under the ambit of Datta Meghe Institute of Medical Sciences University, Wardha, Maharashtra.

- Study Population: With the non-probability convenient sampling method the data was collected. All the females above the age of 14 years attending the hospital in the OPD hours 10 am to $1 \mathrm{pm}$ during the period of month October 2019 to November 2019.Total 100 females were interviewed.

\section{Inclusion Criteria}

Females above the age of 14 years who were willing to give their consent were selected for the study.

\section{Exclusion criteria}

Pregnant and lactating women were excluded from the study.

\section{Methodology}

The study was carried out after obtaining permission from the Institutional Ethics Committee (IEC), Datta Meghe Institute of Medical Sciences (Deemed to be University), Sawangi (Meghe), Wardha, with approval letter no. DMIMS (DU)/IEC/ Sept-2019/8468. The Participants were explained about the nature and purpose of study. Consent was obtained from the participants prior to their recruitment in the study. A self-structured questionnaire was prepared and validated by the subject expert. All the subjects were personally interviewed on the basis of questionnaire. The study was conducted from October 2019 to November 2019. In this period the females above the age of 14 years attending the hospital in the OPD hours 10 am to $1 \mathrm{pm}$ were interviewed. The non-probability convenient sampling method was used to collect data. The time period was fixed and took out from clinical posting period. The special permission was taken from administration to collect the data for research work within these posting hours. The total females visited within this selected period \& responded to our questionnaire with their consent were found to be almost 100. Their data was collected and analysed statistically.

\section{Observation and Result}

Out of sample of 100,the data was analysed on the basis of socio-demographic variables.89\% of respondents were found to have heard of Breast Cancer and $11 \%$ respondents don't have knowledge about this $41 \%$ respondents were found to be aware about Breast lump can be a primary sign of breast cancer.

\section{Table 1: Socio-demographic variables of respondents $(n=100)$ attending Mahatma Gandhi Ayurved Hospital \begin{tabular}{l|l|l} 
Category no. & association of
\end{tabular} Know about BSE* Know about CBE* \\ Know about Mammography \\ (100) Breast lump with} Breast cancer.

\begin{tabular}{|c|c|c|c|c|c|c|c|c|c|c|}
\hline & & & Yes $(\%)$ & No & Yes & No & Yes & No & Yes & No \\
\hline \multirow[t]{5}{*}{ Age } & $\begin{array}{l}\text { 14-19 years } \\
\text { (Teenagers) }\end{array}$ & 5 & $3(60 \%)$ & $2(40 \%)$ & $1(20 \%)$ & $4(80 \%)$ & $0(0 \%)$ & $5(100 \%)$ & $0(0 \%)$ & $5(100 \%)$ \\
\hline & $20-29$ years & 19 & $7(37 \%)$ & $12(64 \%)$ & $5(27 \%)$ & $14(74 \%)$ & $0(0 \%)$ & $19(100 \%)$ & $6(31 \%)$ & $13(69 \%)$ \\
\hline & $30-39$ years & 25 & $12(48 \%)$ & $13(52 \%)$ & $7(28 \%)$ & $18(72 \%)$ & $3(12 \%)$ & $22(88 \%)$ & $1(4 \%)$ & $24(96 \%)$ \\
\hline & $40-49$ years & 18 & $6(34 \%)$ & $12(67 \%)$ & $7(38 \%)$ & $11(62 \%)$ & $2(12 \%)$ & $16(89 \%)$ & $4(22 \%)$ & 14(78\%) \\
\hline & Above 50 & 33 & $18(54 \%)$ & $15(45 \%)$ & $2(7 \%)$ & $31(93 \%)$ & $3(9 \%)$ & $30(90 \%)$ & $3(10 \%)$ & $30(90 \%)$ \\
\hline \multirow[t]{3}{*}{ Education } & $\begin{array}{l}\text { No formal } \\
\text { education }\end{array}$ & 47 & $21(55 \%)$ & $16(45 \%)$ & $5(10 \%)$ & $42(90 \%)$ & $1(3 \%)$ & $46(98 \%)$ & $1(2 \%)$ & $46(98 \%)$ \\
\hline & School level & 41 & $18(44 \%)$ & $23(56 \%)$ & $13(31 \%)$ & $28(69 \%)$ & $2(5 \%)$ & $39(96 \%)$ & $4(9 \%)$ & $37(91 \%)$ \\
\hline & $\begin{array}{l}\text { College/ } \\
\text { University } \\
\text { level }\end{array}$ & 12 & $4(34 \%)$ & $8(67 \%)$ & $4(34 \%)$ & $8(67 \%)$ & $2(17 \%)$ & $10(84 \%)$ & $4(33 \%)$ & $8(67 \%)$ \\
\hline \multirow{3}{*}{$\begin{array}{l}\text { Socio- } \\
\text { economic } \\
\text { Status }\end{array}$} & High & 1 & $0(0 \%)$ & $1(100 \%)$ & $0(0 \%$ & $1(100 \%)$ & $0(0 \%)$ & $1(100 \%)$ & $0(0 \%)$ & $1(100 \%)$ \\
\hline & Middle & 68 & $40(59 \%)$ & $28(41 \%)$ & $18(26 \%)$ & $50(74 \%)$ & $12(18 \%)$ & $56(82 \%)$ & $10(14 \%)$ & $58(86 \%)$ \\
\hline & Low & 31 & $13(42 \%)$ & $18(58 \%)$ & $3(9 \%)$ & $28(91 \%)$ & $2(7 \%)$ & $29(94 \%)$ & $4(12 \%)$ & $27(88 \%)$ \\
\hline \multirow[t]{5}{*}{ Occupation } & Housewife & 25 & $11(44 \%)$ & $14(56 \%)$ & $5(20 \%)$ & $20(80 \%)$ & $1(4 \%)$ & $24(96 \%)$ & $13(52 \%)$ & $12(48 \%)$ \\
\hline & Farming & 25 & $9(36 \%)$ & $16(64 \%)$ & $6(24 \%)$ & $19(76 \%)$ & $0(0 \%)$ & $25(100 \%)$ & $12(48 \%)$ & $13(52 \%)$ \\
\hline & Job & 21 & $12(58 \%)$ & $9(43 \%)$ & $5(23 \%)$ & $16(77 \%)$ & $1(5 \%)$ & $20(95 \%)$ & $4(19 \%)$ & $17(81 \%)$ \\
\hline & Labourer & 5 & $1(20 \%)$ & $4(80 \%)$ & $2(40 \%)$ & $3(60 \%)$ & $0(0 \%)$ & $5(100 \%)$ & $2(40 \%)$ & $3(60 \%)$ \\
\hline & Other & 24 & $10(42 \%)$ & $14(59 \%)$ & $5(20 \%)$ & $19(80 \%)$ & $1(4 \%)$ & $23(96 \%)$ & $4(16 \%)$ & $20(84 \%)$ \\
\hline \multirow{2}{*}{$\begin{array}{l}\text { Marital } \\
\text { Status }\end{array}$} & Married & 78 & $41(53 \%)$ & $37(47 \%)$ & $16(20 \%)$ & $62(80 \%)$ & $9(12 \%)$ & $69(89 \%)$ & $23(30 \%)$ & $55(70 \%)$ \\
\hline & Single & 22 & $10(45 \%)$ & $12(55 \%)$ & $6(28 \%)$ & $16(72 \%)$ & $1(4 \%)$ & $21(96 \%)$ & $4(18 \%)$ & $18(82 \%)$ \\
\hline
\end{tabular}


Total 100 females scrutinised and observations revealed that in all age categories as teenagers, middle age and above 50 years the knowledge, awareness about breast lump is almost below $50 \%$.

On criteria of education it was found that $47 \%$ respondents have no formal education \& $53 \%$ have some level of education. In spite of being educated in both the categories, the knowledge and awareness was below $50 \%$. The observation also revealed that there is no direct correlation between economic status and knowledge, awareness about breast lump. No knowledge and awareness directly related to occupation of women.

The observations were also revealed that the knowledge \& awareness about the screening tools of breast lump like Breast Self-Examination, Clinical Breast Examination and Mammography. It was found close to nil in teenagers, almost $30 \%$ in middle aged females and above 50 years of age, which was the high risk age group it was almost $1 \%$. On the basis of education variable, the screening tools knowledge \& awareness was found to be $10 \%$ in respondents having no formal education and approximately $30 \%$ in respondents having some education. On the basis of socioeconomic status, in lower class it was almost less than $10 \%$ and in the middle class $25 \%$ awareness about BSE was observed but it was less than $20 \%$ for CBE \& mammography. It was observed that there is no direct relation between BSE, CBE and mammography knowledge and occupation and marital status.

Table 2: Respondents attitude towards screening of breast lump with BSE

\begin{tabular}{|c|c|c|c|c|c|c|c|}
\hline \multirow[t]{2}{*}{ Category } & \multirow[t]{2}{*}{ Sub Category } & \multirow{2}{*}{$\begin{array}{c}\text { Total } \\
\text { n } \\
(\mathbf{1 0 0})\end{array}$} & \multicolumn{2}{|c|}{ Perform BSE } & \multicolumn{3}{|c|}{ How often } \\
\hline & & & Yes & No & 15 days & Monthly & $\begin{array}{c}\text { Once in } \\
\text { year }\end{array}$ \\
\hline \multirow[t]{5}{*}{ Age } & 14-19 years (Teenagers) & 5 & $1(20 \%)$ & $4(80 \%)$ & $0(0 \%)$ & $1(20 \%)$ & $0(0 \%)$ \\
\hline & $20-29$ years & 19 & $2(10 \%)$ & $17(90 \%)$ & $1(5 \%)$ & $1(5 \%)$ & $0(0 \%)$ \\
\hline & $30-39$ years & 25 & $4(16 \%)$ & $20(84 \%)$ & $0(0 \%)$ & $2(8 \%)$ & $2(8 \%)$ \\
\hline & $40-49$ years & 18 & $3(16 \%)$ & $15(84 \%)$ & $0(0 \%)$ & $3(16 \%)$ & $0(0 \%)$ \\
\hline & Above 50 & 33 & $1(4 \%)$ & $32(96 \%)$ & $0(0 \%)$ & $0(0 \%)$ & $1(4 \%)$ \\
\hline \multirow[t]{3}{*}{ Education } & No formal education & 47 & $2(5 \%)$ & $45(95 \%)$ & $0(0 \%)$ & $1(3 \%)$ & $1(3 \%)$ \\
\hline & School level & 41 & $8(20 \%)$ & $33(80 \%)$ & $1(3 \%)$ & $5(13 \%)$ & $2(5 \%)$ \\
\hline & College/University level & 12 & $3(25 \%)$ & $9(75 \%)$ & $0(0 \%)$ & $2(16 \%)$ & $1(9 \%)$ \\
\hline \multirow{3}{*}{$\begin{array}{l}\text { Socio- } \\
\text { economic } \\
\text { Status }\end{array}$} & High & 1 & $0(0 \%)$ & $1(100 \%)$ & $0(0 \%)$ & $0(0 \%)$ & $0(0 \%)$ \\
\hline & Middle & 68 & $11(16 \%)$ & $57(84 \%)$ & $1(2 \%)$ & $7(11 \%)$ & $3(5 \%)$ \\
\hline & Low & 31 & $0(0 \%)$ & $31(100 \%)$ & $0(0 \%)$ & $0(0 \%)$ & $0(0 \%)$ \\
\hline
\end{tabular}

Table 2 revealed that $22 \%$ females knew about Breast Self-Examination out of which only $11 \%$ females practiced it in their regular life. $8 \%$ females were found of practicing BSE monthly and $3 \%$ yearly. Educated females were found to be more aware of it. This is the cheapest tool available for screening. In spite of this, negligence towards screening practices was most observed in uneducated women.

Table 3: Respondents attitude towards screening of breast lump with CBE

\begin{tabular}{|c|c|c|c|c|c|c|c|}
\hline \multirow[t]{2}{*}{ Category } & \multirow[t]{2}{*}{ Sub Category } & \multirow{2}{*}{$\begin{array}{c}\text { Total } \\
\mathbf{n} \\
(100)\end{array}$} & \multicolumn{2}{|c|}{ Perform CBE* } & \multicolumn{3}{|c|}{ How often } \\
\hline & & & Yes & No & 15 days & Monthly & $\begin{array}{c}\text { Once in } \\
\text { year }\end{array}$ \\
\hline \multirow[t]{5}{*}{ Age } & 14-19 years (Teenagers) & 5 & $0(0 \%)$ & $5(5 \%)$ & $0(0 \%)$ & $0(0 \%)$ & $0(0 \%)$ \\
\hline & 20-29 years & 19 & $0(0 \%)$ & $19(100 \%)$ & $0(0 \%)$ & $0(0 \%)$ & $0(0 \%)$ \\
\hline & $30-39$ years & 25 & $3(12 \%)$ & $22(88 \%)$ & $0(0 \%)$ & $0(0 \%)$ & $3(12 \%)$ \\
\hline & 40-49 years & 18 & $2(12 \%)$ & $16(88 \%)$ & $0(0 \%)$ & $0(0 \%)$ & $2(12 \%)$ \\
\hline & Above 50 & 33 & $3(10 \%)$ & $30(90 \%)$ & $0(0 \%)$ & $0(0 \%)$ & $3(10 \%)$ \\
\hline \multirow[t]{3}{*}{ Education } & No formal education & 47 & $2(4 \%)$ & $45(96 \%)$ & $0(0 \%)$ & $0(0 \%)$ & $2(4 \%)$ \\
\hline & School level & 41 & $3(8 \%)$ & $38(92 \%)$ & $0(0 \%)$ & $0(0 \%)$ & $3(8 \%)$ \\
\hline & College/University level & 12 & $3(25 \%)$ & $9(75 \%)$ & $0(0 \%)$ & $0(0 \%)$ & $3(25 \%)$ \\
\hline \multirow{3}{*}{$\begin{array}{l}\text { Socio- } \\
\text { economic } \\
\text { Status }\end{array}$} & High & 1 & $0(0 \%)$ & $1(100 \%)$ & $0(0 \%)$ & $0(0 \%)$ & $0(0 \%)$ \\
\hline & Middle & 68 & $8(12 \%)$ & $60(88 \%)$ & $0(0 \%)$ & $0(0 \%)$ & $8(12 \%)$ \\
\hline & Low & 31 & $0(0 \%)$ & $31(100 \%)$ & $0(0 \%)$ & $0(0 \%)$ & $0(0 \%)$ \\
\hline
\end{tabular}

Table 3 revealed that $8 \%$ females knew about $\mathrm{CBE}$ and performed it regularly once a year. Education played a major role. Middle class females were more aware and found to have a good approach as compared to higher $\&$ lower class females.

Table 4: Showing attitude of female of screening breast by different tools after age 40 years $(n=51)$ Perform Mammography $2(4 \%)$ Perform Breast USG $1(2 \%)$ Perform Breast MRI

Respondent's attitude towards screening of breast by different tools after age 40 years was found to be very negligible. 
Ishwari Gaikwad et.al., Knowledge, awareness and attitude about Breast lump among females - An observational study

Table 5: Sources of Information

\begin{tabular}{c|c|c}
\hline Sr No & Source & Percentage \\
\hline $\mathbf{1}$ & Electronic media & $0 \%$ \\
$\mathbf{2}$ & Newspapers & $0 \%$ \\
$\mathbf{3}$ & Doctors & $50 \%$ \\
$\mathbf{4}$ & Community Health Workers & $30 \%$ \\
$\mathbf{5}$ & Nurses & $10 \%$ \\
$\mathbf{6}$ & Internet media & $5 \%$ \\
\hline $\mathbf{7}$ & Social media & $5 \%$ \\
\hline
\end{tabular}

It was found the most active source to create awareness about breast lump were doctors followed by community health workers. Television and Newspapers should take more initiatives in this regards.

\section{Discussion}

Day by day the mortality rate due to cancer is increasing. In women breast cancer is the main cause of death. Awareness and attitude towards screening practices about breast lumps for its early detection is one of the ways to save lots of lives. Education played a role in attitude of respondents. Formal education about screening of breast lumps provides an advantage in the understanding of importance of health awareness. This study revealed that majority of the population had no formal education (42\%). Those who were educated at some level $(57 \%)$ out of them only $50 \%$ have knowledge about breast lump may leads to breast cancer. $25 \%$ respondents have found to be knowledge about the breast lump screening criteria. Out of them 15 $\%$ educated female knew about BSE, $4 \%$ have additional Knowledge of $\mathrm{CBE}$ and $8 \%$ knew about mammography. In spite of knowledge, the attitude towards screening is found to be very disregard. Same findings are supported with the study Peacey V, Steptoe A etal (10). $12 \%$ respondents acknowledged BSE as an early detection measure and $6 \%$ respondents were acknowledged mammography as an early detection measure. It is expected since Mammography is not readily available to the population. So it is expected that very few of respondents aware about it. In spite BSE is non-invasive, readily available \& cheapest method. Still our findings showed that society is deprived away from this knowledge. These findings are supported by previous studies of Nilakshika Ranasingheetal\& of Oluwatosin, O.A., Oladepo, O $(11,12)$. Findings also showed that the recommended clinical breast examination once a year and mammography ones in a three years are not popular. On the other hand, BSE is the cheapest measure and everybody can do it. The awareness about this is found to be $22 \%$ and attitude towards performing is found to be only $8 \%$. On basis of socioeconomic factors, the respondents who were significantly more likely to have done BSE were the married, middle class and had at least school level education. Attitude in lower class female is found to be of negligence. Those having a better knowledge level about screening of breast lump were 30 years of age or older. However, BSE was not significantly associated with any of the attitudes variables towards breast lump knowledge and attitude of screening. Majority of our respondents did not know about mammography and CBE.
The leading sources of information were doctors and health care workers. This finding is similar to those of previous studies conducted by Ranasinghe \& Rodrigo, C. et al (13). It is understandable that health care workers and doctors have consistently been reported as the leading source of information. Medias are the second leading source of information. The same findings are supported by Oluwatosin, O.A., Oladepo, O study (12). Developing proper health practices should commence as early as possible, and should lead to lifetime maintenance of good health. Adolescent females are an important target group for promotion of proper health habits, in particular with regards to breast health. Illustrated participants knowledge and the frequency of application of breast examination suggested requirement of active intervention.

\section{Conclusion}

The study concludes that the respondents didn't have adequate knowledge and awareness about Breast lump or mass. This study highlights the need for educational program to create awareness regarding Breast lump and its occurrence, screening criteria including BSE, CBE, Mammography, USG Breast, MRI Breast all these facilities are available for it. There is need of early detection and diagnosis in case of breast cancer. Training all health care providers on BSE is the way to propagate BSE skills across various communities. Different Medias like television, newspapers should active propagate this knowledge and create awareness in society. Female's attitude to be changed about screening of breast lumps.

\section{Limitation of Study}

The project was taken as short term project among female patients visiting to OPD. So to plan the intervention for awareness in society we cannot identify the need required as per age.

\section{References:}

1. Malik M, Salahuddin O, Azhar M, Dilawar O, Irshad H, Sadia SA et.al. Breast diseases spectrum in Wahcantt : POF hospital experience. Professional Med Journal. 2010; 17(3):366-72.

2. National Centre for Disease Informatics and Research. Three Year Report of Population Based Cancer Registries 2009-2011 National Cancer Registry Programme. 2009-2011 
3. Mansoor I. Profile of female breast lesions in Saudi Arabia. JPMA. 2001; 51(7):243-6.

4. Lam WW, Chan CP, Chan CF, Mak $\mathrm{CC}$ et al. Factors affecting the palpability of breast lesion by self-examination. Singapore Med J. 2008; 49:228-3

5. Hislop T, Elwood J. Risk factors for benign breast disease: A 30-year cohort study. Can Med Assoc J. 1981; 124(3):283.

6. Eddo OA, Ugiagbe EE. Benign breast lesions in an African population: A 25-year histopathological review of 1864 cases. Niger J Med. 2011; 52(4):211

7. Morrow M. Evaluation of common breast problems. Am Fam Physician. 2000; 61(8):2371-78

8. Gupta A, Shridhar K, Dhillon PK. A review of breast cancer awareness among women in India: Cancer literate or awareness deficit? Eur J Cancer. 2015; 51:2058-66

9. Dubsky PC, Gnant MF, Taucher S, Roka S, Kandioler D et al. Young age as an independent adverse prognostic factor in premenopausal patients with breast cancer. Clin Breast Cancer Journal.2002, 3: 65-72.

10. Peacey V, Steptoe A, Davidsdottir S, Baban A, Wardle J: Low levels of breast cancer risk awareness in young women: an international survey. Eur J Cancer. 2006, 42: 2585-2589.

11. Nilakshika Ranasinghe, Chaturaka Rodrigo, Rohini De. A Seneviratne Senaka Rajapakse Awareness Of Breast Cancer Among Adolescent Girls in Colombo, Sri Lanka: A School Based Study,BMC Public Health.2002, 3: 65-72.

12. Oluwatosin, O.A., Oladepo, O. Knowledge of breast cancer and its early detection measures among rural women in Akinyele Local Government Area, Ibadan, Nigeria. BMC Cancer 6, 2006, 271

13. Ranasinghe, H.M., Ranasinghe, N., Rodrigo, C. et al. Awareness of breast cancer among adolescent girls in Colombo, Sri Lanka: a school based study. BMC Public Health13, 2013, 1209. 